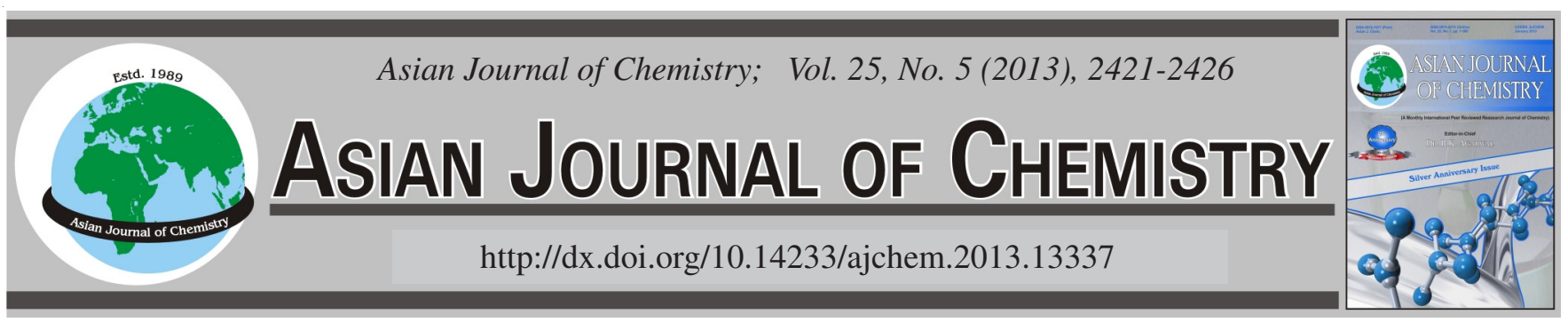

\title{
Application of Response Surface Methodology for Optimization of Cellulose Solution by Zinc Chloride
}

\author{
G.M. Zeng ${ }^{1}$, Y.L. WANG ${ }^{1, *}$ X.X. QING ${ }^{2}$, M.L. ZHANG ${ }^{1}$, J. XING ${ }^{1}$, Y.F. MA ${ }^{1}$ and H.J. XU ${ }^{1}$
}

${ }^{1}$ Key Laboratory of Biorheological Science and Technology for Ministry of Education and Center of Bioinspired Materials Science and Engineering of National "985 Project Program", College of Bioengineering, Chongqing University-Sha Zheng Street, Chongqing, P.R. China ${ }^{2}$ Key Laboratory of Three Gorges Reservoir Region Eco-environment of Ministry of Education,Chongqing University, Chongqing, P.R. China

*Corresponding author: E-mail: zeng373064894@126.com; qxx118@126.com

\begin{abstract}
Corn stover is a largely feasible and cheap renewable resource with low commercial value. An attractive alternative is utilization of corn stover for chemical industry, medicine, biochemistry etc. However, the production costs are still too high to apply on commercialization. The objective of this study was to use the response surface methodology (RSM) to optimization of cellulose salvation by zinc chloride after the steam explosion and characterization and map changes during zinc chloride pretreatments of corn stover. The solution of cellulose had been pretreated with $87 \%$ zinc chloride at $139^{\circ} \mathrm{C}$ for 49 min resulted in an optimum solubility of $76.2 \%$. Zinc chloride pretreatment apparently damaged the surface of cellulose and significantly decreased the crystalline region, as evidenced by SEM and XRD analysis data. FTIR analysis indicated that zinc chloride pretreatment could breakage the hydrogen bond of crystalline region of the cellulose. The zinc chloride after steam explosion technique, as a novel pretreatment method, decreased crystalline region of cellulose by changing structural features.
\end{abstract}

Key Words: Cellulose, Response surface methodology, Zinc chloride solution, Solubility.

\section{INTRODUCTION}

As decreasing of fossil fuels and increasing energy demand, the earth encounters a serious problems,especially the liquid fuels. Biofuels production from various lignocellulosic materials, such as corn stover, is a potential and feasible method to solve the huge complex problems and also supported by many governments ${ }^{1,2}$. Corn stover is a kind of lignocellulosic biomass which is most abundant and renewable resource for bioconversion into fermentable sugars on earth, which can be further utilized for biofuel production ${ }^{3,4}$. But corn stover has a complex structure in which hemicellulose, lignin and cellulose are the major components. During the process of transforming corn stover to fermentable sugars, the physico-chemical and structural features of the biomass affect the enzyme accessibility and activity ${ }^{5}$. Meanwhile as a result of high crystalline cellulose, the strong inter chain hydrogen-bonding network is resistant to enzymatic hydrolysis, whereas hemicellulose and amorphous cellulose are readily digested.

Pretreatment is an essential step for enzymatic hydrolysis in the production of biofuel from lignocellulosic biomass. Recently, steam explosion has been comprehensively used to pretreat lignocellulosics for biofuel production ${ }^{6}$. Compared with traditionary pretreatment methods, the advantages of steam explosion include a significantly lower environmental impact, lower capital investment, less hazardous chemical process and much more amorphous composions can be selectively removed ${ }^{7}$. It can results in substantial breakdown of the lignocellulosic structure, hydrolysis of the hemicellulosic fraction, depolymerization of the lignin components. So the accessibility of the cellulose components by enzymes is greatly increased.

The solution of cellulose is a fundamental step for chemical industry, medicine and spinning process. Now several new solvent systems for cellulose has been studied, such as nonderivatization, $\mathrm{N}$-methyl-morpholine-N-oxide monohydrate ${ }^{8}$ (NMMNO-MH), mixtures of organic and inorganic substances like dimethyl acetamide/ $\mathrm{LiCl}^{9}$, ion liquids, aqueous solutions of transition metal complexes ${ }^{10}$, concentrated aqueous salt solutions like zinc chloride $/ \mathrm{H}_{2} \mathrm{O}^{11}$ and $\mathrm{Ca}(\mathrm{SCN})_{2} / \mathrm{H}_{2} \mathrm{O}^{12}$ and molten salt hydrates like $\mathrm{LiSCN} \cdot 2 \mathrm{H}_{2} \mathrm{O}^{13}$. Compared with these, the advantages of zinc chloride include stable, small pollution and recover easily.

Response surface methodology (RSM) is a statistical technique for the modeling and optimization of multiple variables, which determines optimum process conditions by combining 
experimental designs with interpolation by first- or secondpolynomial equations in a sequential testing procedure ${ }^{14}$.

The overall goal of this work was to investigate the feasibility of improving the solution of cellulose by zinc chloride after steam explosion. Response surface methodology (RSM) were employed for experimental design, in order to evaluate the effects of zinc chloride concentration, reaction temperature and reaction time on cellulose solution and also discussed the morphology and chemical properties of corn stover after the pretreatment of zinc chloride.

\section{EXPERIMENTAL}

Corn stover used in the experiments was harvested at maturity in October 2009 from Zhong Liang-shan in Chong Qing, China. The air-dried corn stover was milled to powder. The particles passed through a 60-mesh and were stored in a sealed plastic bag at room temperatures. The chemical compositions of corn stover were $25.8 \%$ cellulose, $34.5 \%$ hemicelluloses, $7.3 \%$ lignin and ash. All chemicals used were of analytical grade. The machine of steam explosion were purchased from Zheng Dao (Henan).

\section{General procedure}

Steam explosion pretreatment: The steam explosion experiments were carried out in a bench scale equipment, which consists one steam generator, two pressurized reactor (with a maximum operating pressure of 5.0 MPa) fitted with a quick-opening pressure relief valve and one receivers. Steam explosion operations were carried out using the same amount of corn stover ( $50 \mathrm{~g}$ of dry matter) each batch. After placing the material manually, high temperature steam was applied to reach a predetermined pressure $(2.2 \mathrm{MPa})$. When the expected fixed residence time $(9 \mathrm{~min})$ was reached, the pressure relief valve was auto-opened to release the pressure and then the exploded samples were washed with distilled water 5 times and then collected and oven-dried at $70{ }^{\circ} \mathrm{C}$ for $24 \mathrm{~h}$. All experiments were performed at least in duplicate and analyses were carried out at least three times for each of the samples. The standard errors or deviations of the analyses were observed to be lower than $5 \%$.

Zinc chloride pretreatment: The single factor experiment was performed to confirm the optimal conditions, which were the zinc chloride concentration, the reaction time and the reaction temperature. First, each Wolff bottle with $0.5 \mathrm{~g}$ dry samples and $50 \mathrm{~mL}$ different zinc chloride concentration (70-95\%) solution were mixed together for $0.5 \mathrm{~h}$ before heated, the purpose of which was to make them contact completely. Then the Wolff bottle was heated to the target temperature of $130{ }^{\circ} \mathrm{C}$ for $1 \mathrm{~h}$ in an oil bath. When the reaction ended, the Wolff bottle was transferred to room-temperature to complete the reaction. The contents of the Wolff bottle were washed out with distilled water into a $50 \mathrm{~mL}$ centrifuge tube, followed by centrifugation to separate the liquid and solid residue and then added $200 \mathrm{~mL}$ water into the liquid make it precipitate the regenerated cellulose and oven-dried at $70{ }^{\circ} \mathrm{C}$, weighted it to determine the best concentration. Then optimum the reaction time under the optimal zinc chloride concentration, among 15-90 min. Finally, determine the best reaction temperature under the optimal zinc chloride concentration and reaction time, among $110-160{ }^{\circ} \mathrm{C}$.

Experimental design: Response surface methodology (RSM) is a collection of mathematical and statistical techniques, is usually used for modeling and analyzing problems in which a response of interest is affected by several variables and the aim is to optimize the response. The solution of cellulose was treated as the response influenced by many potential variables. Five variables, including substrate concentration, agitation, zinc chloride concentration, reaction time and reaction temperature were studied and it was found that the three of them (zinc chloride concentration, reaction time and reaction temperature) made greater contribution to the solution of cellulose than the other two. The range and center point values of these three factors are shown in Table-1. Based on the results of previous, the experiment was further expanded to a BoxBehnken $^{15}$. The Box-Behnken design consisted of 15 experiments including three replicates of the central point (Table-2). All statistical and mathematical analysis of the results from Box-Behnken was done by Minitab 15. Both linear and quadratic effects of the three variables were calculated, as well as their possible interactions, on solution of cellulose. Their significance was evaluated by variance analysis (ANOVA). 3D surface plots were drawn to show the effects of independent variables on the response. A quadratic polynomial equation was proposed to describe the mathematical relationship between the response and the variables. The fit of the model was evaluated by the determination of $\mathrm{R}^{2}$ and adjusted $\mathrm{R}^{2}$ coeffcient. The validation of the model optimum value of selected variables was obtained by solving the regression equation using Minitab 15. The predicted optimum value was confirmed by the experiment using the selected optimum values of the three variables. For statistical calculations, the relation between the coded values and real values are described as follows:

TABLE-1

LEVELS OF FACTORS VARIOUS EMPLOYED IN THE PRESENT STUDY FOR THE CONSTRUCTION OF BOX-BEHNKEN

\begin{tabular}{lccc}
\hline \multirow{2}{*}{\multicolumn{1}{c}{ Factors }} & \multicolumn{3}{c}{ Levels } \\
\cline { 2 - 4 } & -1 & 0 & 1 \\
\hline $\mathrm{X}_{1}$ concentration $(\%)$ & 80 & 85 & 90 \\
$\mathrm{X}_{2}$ temperature $\left({ }^{\circ} \mathrm{C}\right)$ & 130 & 140 & 150 \\
$\mathrm{X}_{3}$ time (min) & 30 & 45 & 60 \\
\hline
\end{tabular}

$$
\mathrm{x}_{\mathrm{i}}=\frac{\mathrm{X}_{\mathrm{i}}-\mathrm{X}_{0}}{\Delta \mathrm{X}}
$$

where $\mathrm{X}_{\mathrm{i}}$ is dimensionless coded value of the variable $\mathrm{X}_{\mathrm{i}}, \mathrm{X}_{0}$ is the real value of the $X_{i}$ at the center point; and $\Delta X$ is the step change of variable. The behaviour of the system was explained by the following quadratic equation:

$$
\mathrm{Y}=\beta_{0}+\Sigma \beta_{\mathrm{i}} \mathrm{x}_{\mathrm{i}}+\Sigma \beta_{\mathrm{ii}} \mathrm{x}_{\mathrm{i}}^{2}+\Sigma \beta_{\mathrm{ij}} \mathrm{x}_{\mathrm{i}} \mathrm{x}_{\mathrm{j}}
$$

where $Y$ is the predicted response, $\beta_{0}$ the intercept term, $\beta_{i}$ the linear coefficient, $\beta_{\mathrm{ii}}$ the squared coefficient and $\beta_{\mathrm{ij}}$ is the interaction coefficient.

Detection method: Fourier transform infrared (FT-IR) spectra were recorded in 4000-400 $\mathrm{cm}^{-1}$ region using a Spectrum GX (Perkin Elmer, US). Discs were prepared by 


\begin{tabular}{ccccc}
\hline \multicolumn{5}{c}{ TABLE-2 } \\
\multicolumn{5}{c}{ EXPERIMENTAL DESIGN OF ZINC CHLORIDE } \\
CONCENTRATION $\left(\mathrm{X}_{1}\right)$, REACTION TEMPERATURE \\
$\left(\mathrm{X}_{2}\right)$, REACTION TIME $\left(\mathrm{X}_{3}\right)$ AND THE RESULTS \\
\hline \multicolumn{5}{c}{ FOR CELLULOSE SOLUTION ${ }^{\mathrm{a}}$} \\
\hline Runs & $\mathrm{X}_{1}$ & $\mathrm{X}_{2}$ & $\mathrm{X}_{3}$ & Solution $(\mathrm{g})$ \\
\hline 1 & -1 & -1 & 0 & 0.640 \\
2 & -1 & 1 & 0 & 0.640 \\
3 & 1 & -1 & 0 & 0.740 \\
4 & 1 & 1 & 0 & 0.698 \\
5 & 0 & -1 & -1 & 0.690 \\
6 & 0 & -1 & 1 & 0.720 \\
7 & 0 & 1 & -1 & 0.662 \\
8 & 0 & 1 & 1 & 0.740 \\
9 & -1 & 0 & -1 & 0.587 \\
10 & 1 & 0 & -1 & 0.726 \\
11 & -1 & 0 & 1 & 0.690 \\
12 & 1 & 0 & 1 & 0.720 \\
13 & 0 & 0 & 0 & 0.760 \\
14 & 0 & 0 & 0 & 0.762 \\
15 & 0 & 0 & 0 & 0.761 \\
\hline
\end{tabular}

${ }^{a}$ Values in parentheses represent the amount of each component recovered from $1.000 \mathrm{~g}$ total corn stover

mixing $2 \mathrm{mg}$ dried sample with $120 \mathrm{mg} \mathrm{KBr}$ then pressed in a standard device using a pressure of $16 \mathrm{MPa}$ to produce $13 \mathrm{~mm}$ diameter pellets. The background spectrum of pure potassium bromide was subtracted from that of the sample spectrum. Crystalline structure of the cellulose rich sample was determined by X-ray diffraction using a Rigaku X-ray diffractometer (Rigaku D/MAX 2500PC Japan) with $\mathrm{CuK}_{\alpha}$ radiation $(\mathrm{k}=$ $1.5406 \AA$ ); the operation voltage and current were maintained at $40 \mathrm{kV}$ and $150 \mathrm{~mA}$, respectively. The $2 \theta$ range was from $5-40^{\circ}$ in steps of $0.02^{\circ} / 2 \theta$ with continuous scan. Scanning electron microscopy was conducted to analyze the microstructural changes and surface characteristics of untreated and pretreated corn stalk. Samples of untreated and pretreated corn stalk were studied using a TESCAN VEGAIILMU scanning electron microscopy, where samples were coated with a thin layer of gold in an automatic sputter coater before observation. The accelerating voltage was $10 \mathrm{kV}$ and images of the samples were acquired at 1000 magnification.

\section{RESULTS AND DISCUSSION}

Experimental results of single factor experiment: To determine the optimization of zinc chloride concentration, reaction time and reaction temperature on cellulose solution, the single factor of experimental condition with the corresponding solution are shown in Fig. 1(a-c). The effect of zinc chloride concentration range from $70-95 \%$ at $130{ }^{\circ} \mathrm{C}$ for $1 \mathrm{~h}$ on the cellulose after steam explosion is given in Fig. 1(a). As can be seen, with the increasing of zinc chloride concentration, the solution of cellulose grew quickly, but when it reach $85 \%$, it is scarcely increase, we chose the optimal of zinc chloride concentration is $85 \%$. Similarly, we determined the optimal of reaction temperature (Fig. 1b) and reaction time (Fig. 1c) is $140{ }^{\circ} \mathrm{C}$ and $45 \mathrm{~min}$, respectively.

RSM for optimization of cellulose solution: Three factors $\mathrm{X}_{1}$ (zinc chloride concentration), $\mathrm{X}_{2}$ (reaction temperature) and $\mathrm{X}_{3}$ (reaction time) were selected and further optimized using Box-Behnken design in RSM to determine the optimal values for each of the factors. The levels of the factors and the

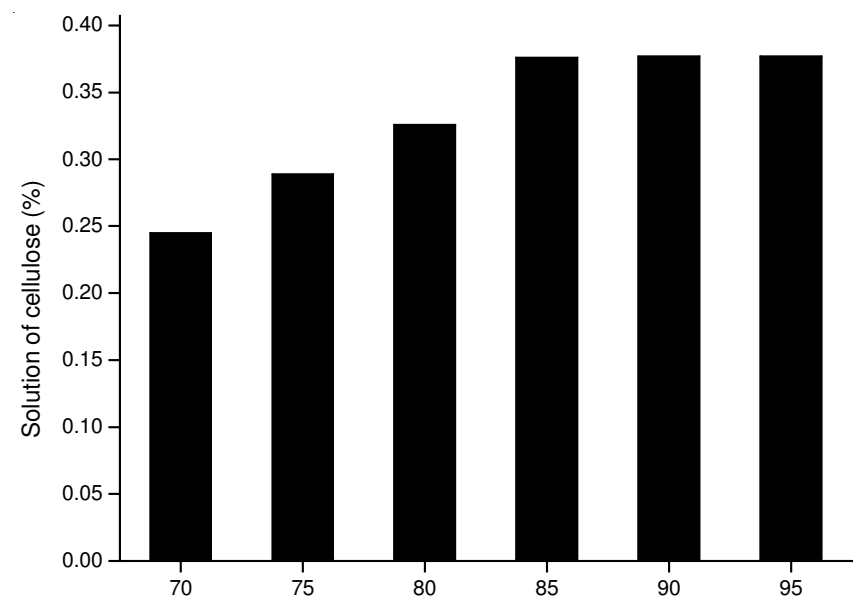

(a) Zinc chloride concentration (\%)

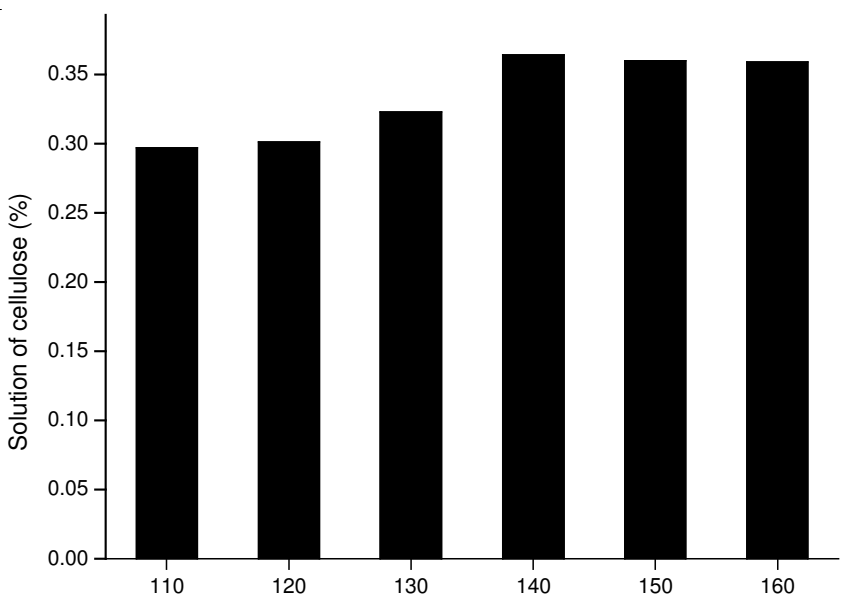

(b) Reaction temperature $\left({ }^{\circ} \mathrm{C}\right)$

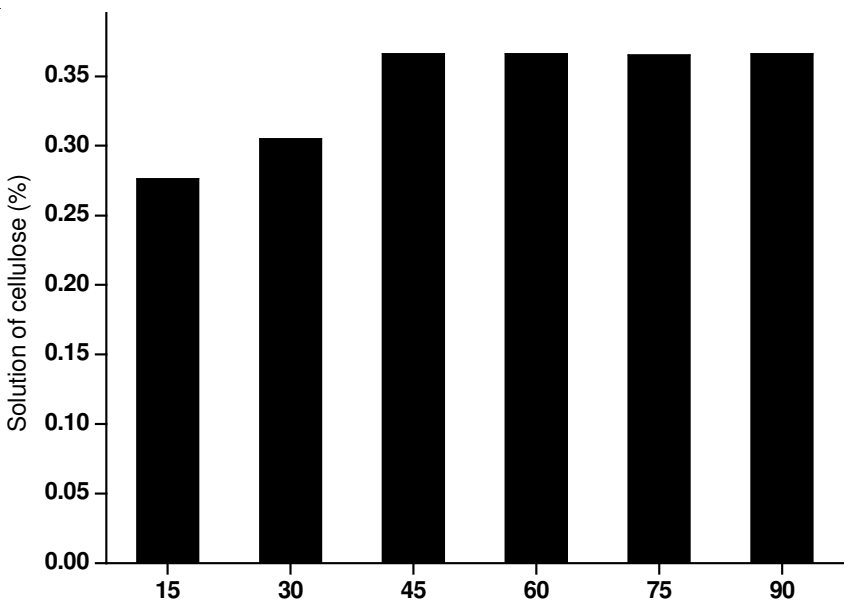

(c) Reaction time (min)

Fig. 1. Effect of different pretreatment methods on the solution of cellulose (a) concentration $(b)$ reaction temperature (c) reaction time

experimental design are shown in Tables 3 and 4. The results were analyzed by standard analysis of variance (ANOVA) and the Box-Behnken design was fitted with the second-order polynomial equation:

$$
\begin{gathered}
Y=0.761+0.41 X_{1}-0.00625 X_{2}+0.02575 X_{3}-0.0105 X_{1} \times \\
X_{2}-0.0275 X_{1} \times X_{3}+0.012 X_{2} \times X_{3}-0.052 X_{1}^{2}-0.0295 X_{2}^{2} \\
-0.0285 X_{3}^{2}
\end{gathered}
$$


SIGNIFICANCE TEST FOR REGRESSION COEFFICIENT

\begin{tabular}{lcccc}
\hline \multicolumn{1}{c}{ Term } & Coefficient & $\begin{array}{c}\text { Standard error } \\
\text { Coefficient }\end{array}$ & T Ratio & P-Value \\
\hline Constant & 0.761000 & 0.004704 & 161.787 & 0.0000 \\
$\mathrm{X}_{1}$ & 0.041000 & 0.002352 & 17.433 & $<0.00001$ \\
$\mathrm{X}_{2}$ & -0.006250 & 0.002352 & -2.657 & 0.0057 \\
$\mathrm{X}_{3}$ & 0.025750 & 0.002352 & 10.949 & $<0.00001$ \\
$\mathrm{X}_{1}{ }^{2}$ & -0.052000 & 0.003719 & -13.984 & $<0.00001$ \\
$\mathrm{X}_{3}{ }^{2}$ & -0.029500 & 0.003719 & -7.933 & 0.001 \\
$\mathrm{X}_{3}{ }^{2}$ & -0.028500 & 0.003719 & -7.664 & 0.002 \\
$\mathrm{X}_{1} \mathrm{X}_{2}$ & -0.010500 & 0.003326 & -3.157 & 0.034 \\
$\mathrm{X}_{1} \mathrm{X}_{3}$ & -0.027500 & 0.003326 & -8.268 & 0.001 \\
$\mathrm{X}_{2} \mathrm{X}_{3}$ & 0.012000 & 0.003326 & 3.608 & 0.023 \\
$\mathrm{~S}^{2}$ & $\mathrm{PRESS}=$ & - & - & - \\
0.00665207 & 0.002808 & & & \\
$\mathrm{R}-\mathrm{Sq}=$ & $\mathrm{R}-\mathrm{Sq}=$ & $\mathrm{R}-$ Sq $=98.30$ & & \\
$99.48 \%$ & $91.72 \%$ & $\%$ & & \\
\hline Note: $p<0.01$, most significant difference, $p<0.05$, & significant \\
difference. The same below. & &
\end{tabular}

Using Minitab 15, an analysis of variance was conducted for evaluation of the effects of the variables and their probably existed interactions. Coefficients of the full model were analyzed for their significance and the insignificant ones were eliminated from the model by backward elimination. The reduced model was adjusted after all the insignificant variables ( $p$-value $>0.05$ ) were excluded. The results of ANOVA for the adjusted model are shown in Table-3. The $p$-value of the adjusted model was lower than 0.0001 indicating that the model is statistically valid. And the $p$-values of $X_{1}, X_{3}$ and $X_{1}^{2}$ were all lower than 0.0001 demonstrating that they were the most significant factors than the other ones influencing the response. $\mathrm{X}_{1} \mathrm{X}_{2}, \mathrm{X}_{2} \mathrm{X}_{3}, \mathrm{X}_{1} \mathrm{X}_{3}$, were also significant factor with $p$-value 0.0005 manifesting that there were interaction existing between the $\mathrm{X}_{1}$ and $\mathrm{X}_{2}, \mathrm{X}_{3}$ and $\mathrm{X}_{2}, \mathrm{X}_{1}$ and $\mathrm{X}_{3}$, respectively. According to Table- 4 , the $\mathrm{R}^{2}$-value was 0.9974 in good agreement with the adjusted $\mathrm{R}^{2}$-value of 0.99478 . The vicinity of adjusted $\mathrm{R}^{2}$ to $\mathrm{R}^{2}$ means a good adjustment of the theoretical values to the experimental data by the model. At the same time the lack of fit was insignificant but the $\mathrm{R}^{2}$-value (0.9974) was high indicating that the model was well adapted to the response. So the adjusted model was suitable to predict the experimental data from solution of cellulose.

Based on these observations (eqn. 1), three-dimensional surface plots were constructed to determine the levels of the processing factors that contribute to reaching the optimal solution of cellulose (Fig. 1). The interactions between two variables were depicted by keeping the other variables at their optimal levels for cellulose solution. It could be clearly seen that the highest cellulose solution should locate at the zinc chloride concentration and reaction temperature ranging $85-90{ }^{\circ} \mathrm{C}$ and $140-150{ }^{\circ} \mathrm{C}$, respectively (Fig. 1a). By setting reaction temperature and reaction time in the range of 140$150{ }^{\circ} \mathrm{C}$ and $45-50 \mathrm{~min}$, respectively (Fig. 1b), the optimal cellulose solution should be achieved. The highest cellulose solution should locate at the zinc chloride concentration and reaction time ranging $85-90 \%$ and $45-50 \mathrm{~min}$, respectively (Fig. 1c).

\section{Experimental validation of the optimized condition:}

The optimal solution for the three components was obtained from the model were $87 \%, 139^{\circ} \mathrm{C}$ and $45 \mathrm{~min}$ for zinc chloride concentration, reaction temperature and reaction time, respectively. In order to verify the optimization results, three experiments in test tubes were performed under the predicted optimal conditions. The mean solution of cellulose was $76.2 \%$, which was close to the solution predicted by RSM $(76.1 \%)$.

Crystallinity analysis: The crystallinity of the lignocellulosic has been regarded as a major factor that influences enzymatic hydrolysis ${ }^{16}$. We performed X-ray diffraction used for the investigation of crystallinity of cellulose. The XRD spectra of samples (a), untreated (b) steam explosion (2.2 Mpa, $9 \mathrm{~min}$ ), (c) and zinc chloride-treated corn stover after steamexploded were showed in Fig. 2. The (a) and (b) have typical cellulose I diffraction angles around 14.9 and $22.6^{\circ}$. For the corn stalk treated by zinc chloride, diffraction angles around 14.9 and $22.6^{\circ}$ decreased much, this indicated that an amorphous structure with great change. During the steam explosion and fractional process, the hemicellulose and other materials in the corn stalk were removed, the relative content of cellulose increased. So the crystalline polymorphism was not destroyed. But crystalline structure of corn stalk was transformed into amorphous after treatment by zinc chloride. Probably, during the regeneration process, the rapid precipitation with alcohol prevented the dissolved corn stalk from restructuring into its original crystalline structure. As consequence, the regenerated corn stalk with amorphous structure could provide more surfaces for enzymes to attack on. So it could conclude that the intact structure was disrupted by zinc chloride treatment and resulted in a transformation from the cellulose I into amorphous form.

FT-IR spectroscopy: FT-IR spectroscopy is an analytical that has been used to identify polysaccharides, check their purity, determine structure and investigate complex and intermolecular interactions ${ }^{17}$. Fig. 3 show all the untreated corn stover, steam-exploded samples and zinc chloride-treated corn stover after steam-exploded.

\begin{tabular}{|c|c|c|c|c|c|c|}
\hline \multicolumn{7}{|c|}{$\begin{array}{c}\text { TABLE-4 } \\
\text { VARIANCE ANALYSIS OF REGRESSION EQUATION }\end{array}$} \\
\hline Source & $\mathrm{df}$ & Seq SS & Adj SS & Adj MS & F Ratio & P-Value \\
\hline Regression & 9 & 0.033739 & 0.033739 & 0.003749 & 84.72 & $<0.0001$ \\
\hline Linear & 3 & 0.019065 & 0.019065 & 0.006355 & 143.62 & $<0.0001$ \\
\hline Square & 3 & 0.010632 & 0.010632 & 0.003544 & 80.09 & 0.001 \\
\hline Interaction & 3 & 0.004042 & 0.004042 & 0.001347 & 30.45 & 0.003 \\
\hline Residual error & 4 & 0.000177 & 0.000177 & 0.000044 & - & - \\
\hline Loss of the proposed & 3 & 0.000175 & 0.000175 & 0.000058 & 29.17 & 0.135 \\
\hline Pure error & 1 & 0.000002 & 0.000002 & 0.00000 & - & - \\
\hline Correlation coefficient & 0.9974 & - & - & - & - & - \\
\hline Correction coefficient & 0.99478 & - & - & - & - & - \\
\hline
\end{tabular}




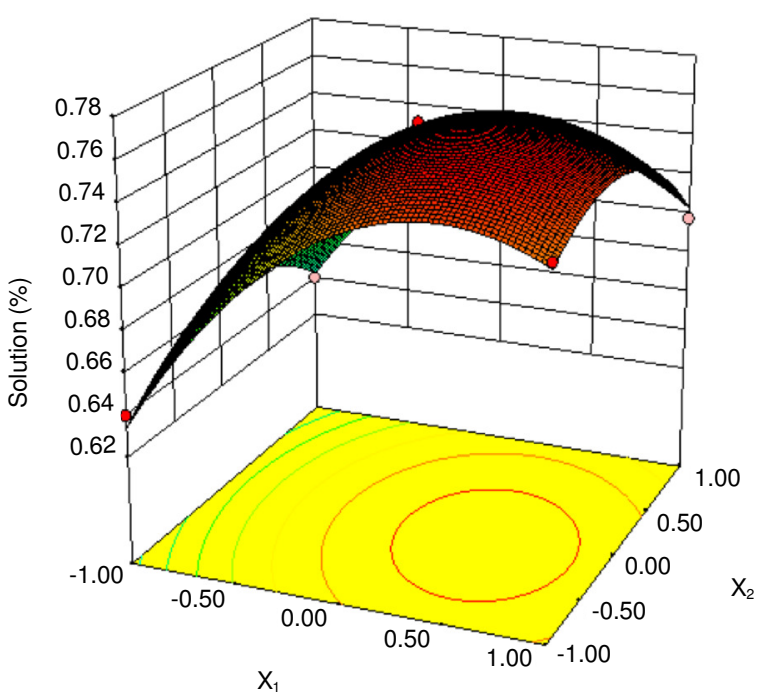

(a)

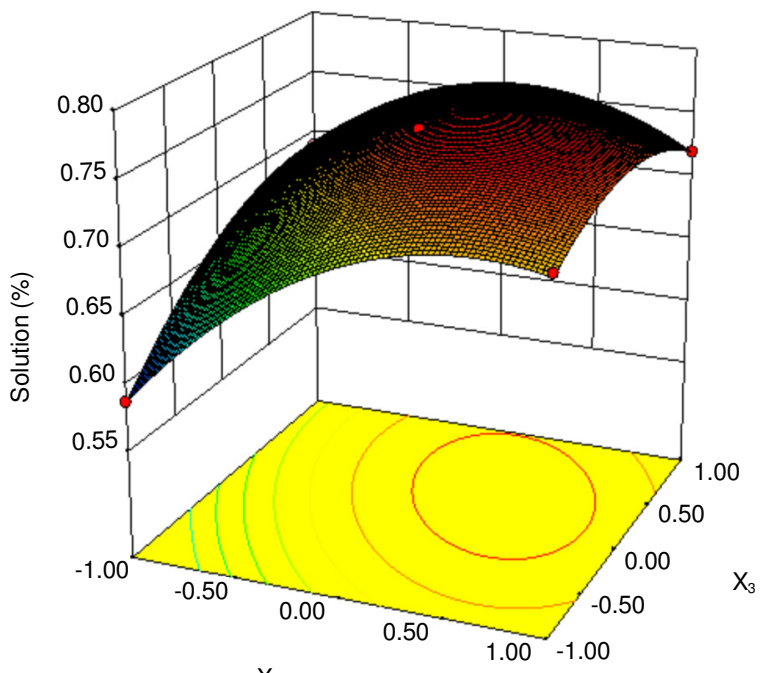

$X_{1}$

(b)

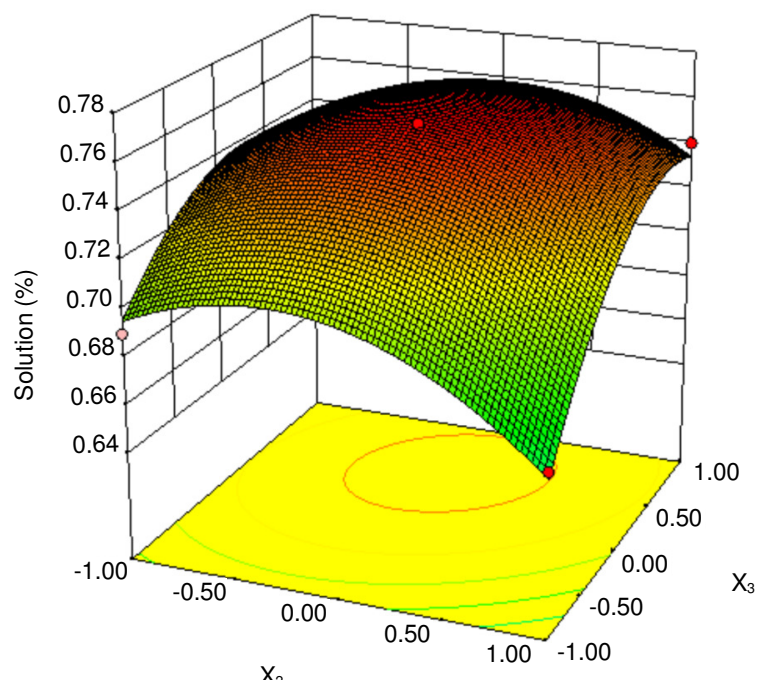

(c)

Fig. 2. 3D response surface contour plots showing the experimental factors and their mutual interactions on cellulose solution (A) zinc chloride concentration $\left(\mathrm{X}_{1}\right)$ and reaction temperature $\left(\mathrm{X}_{2}\right)(\mathrm{B})$ zinc chloride concentration $\left(\mathrm{X}_{1}\right)$ and reaction time $\left(\mathrm{X}_{3}\right)(\mathrm{C})$ reaction temperature $\left(\mathrm{X}_{2}\right)$ and reaction time $\left(\mathrm{X}_{3}\right)$

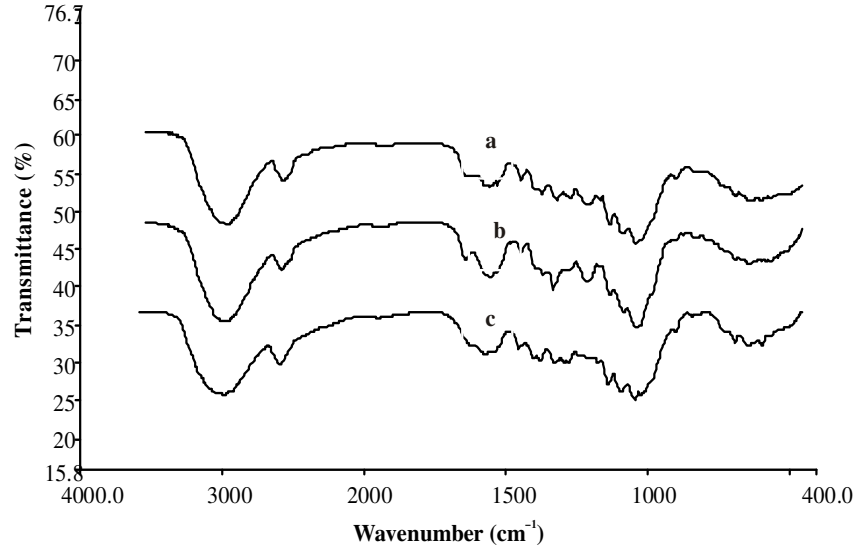

Fig. 3. FT-IR spectra of the cellulose rich fractions (a: untreated, b: steam explosion treated, c: zinc chloride-treated corn stover after steamexploded)

It can be seen that all the spectra are typical style of native cellulose. The absorption at 3390 and $2920 \mathrm{~cm}^{-1}$ are attributed to $\mathrm{C}-\mathrm{H}$ stretching ${ }^{18}$, respectively, corresponding to the aliphatic moieties in cellulose and survived lignin (or hemicelluloses). The $\mathrm{C}-\mathrm{H}$ bending occurs at $1380 \mathrm{~cm}^{-1}$. Two absorption bands at 1160 and $898 \mathrm{~cm}^{-1}$ arise from C-O-C stretching at the b-(1/4)-glycosidic linkages ${ }^{19}$. The most important bands that helped to identify the cellulose component are: $1426 \mathrm{~cm}^{-1}$, attributed to amorphous cellulose and crystallized cellulose II and $1380 \mathrm{~cm}^{-1}$, attributed to crystallized cellulose I. The spectrum obtained from the cellulose-rich fraction of original material showed a band around $1426 \mathrm{~cm}^{-1}$, indicated that it contained a mixture of crystallized cellulose I and amorphous cellulose ${ }^{20}$. It is worth noting that, after steam explosion pretreatment, the intensity of this peak shifted to $1427 \mathrm{~cm}^{-1}$, indicating the increasing ratio of crystalline to amorphous cellulose. In comparison to zinc chloride pretreatment, it resulted in more severe degradation. After zinc chloride pretreatment, the intensity of peak at $1100 \mathrm{~cm}^{-1}$ decreased, it revealed that the bonding of $\mathrm{C}-\mathrm{O}-\mathrm{C}$ breakage at some degree, which suggested the degree of polymerization of cellulose decreased. Meanwhile the peak at $1000 \mathrm{~cm}^{-1}$ shifted obviously, which revealed that the crystallinity of cellulose decreased, but the none-crystallinity increase after zinc chloride pretreatment.

Morphological analysis of corn stover by SEM: As can be seen, the surface of untreated corn stover is smooth and arranged compactly around the fiber. Small fragments were dislodged from the scales and the surface was damaged by the steam explosion. Mean while, length-wise grooves were produced on the surface of the scales after the pretreatment. Zinc chloride pretreatment could disrupt recalcitrant structures in the biomass and orderly hydrogen bonds in crystalline cellulose $^{21}$ and increase the accessibility of cellulase to cellulose. zinc chloride pretreatment at a temperature of $139^{\circ} \mathrm{C}$ resulted in damage to the intact cell structure and increased the exposure of the internal structure of the cell (Fig. 4), which would certainly increase the external surface area. Moreover, the pretreated sample was much softer and more amenable to digestion than the untreated sample. 


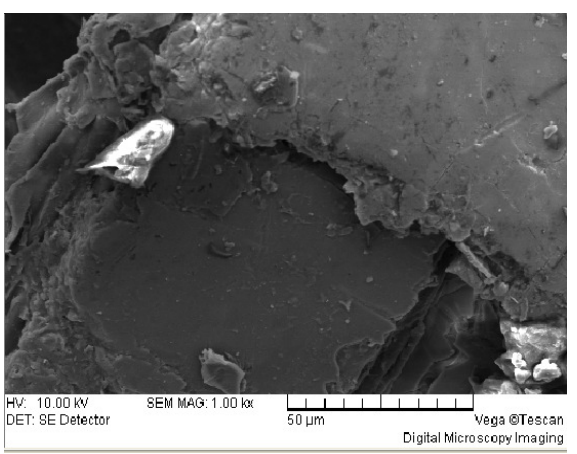

(a)

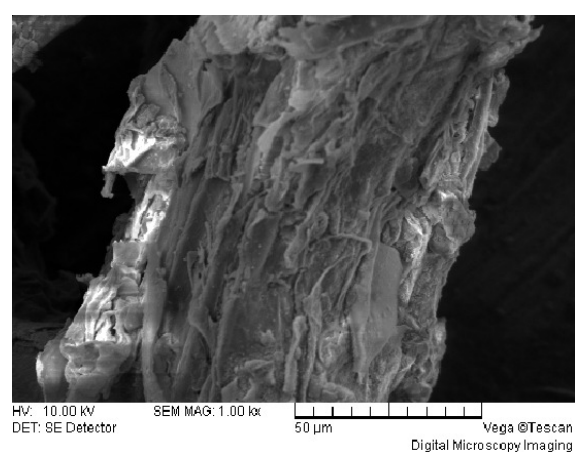

(b)

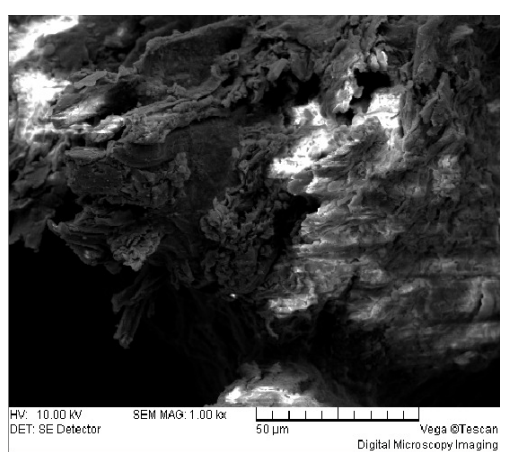

(c)

Fig. 5. SEM of the cellulose rich fractions (a): untreated, (b) steam explosion treated, (c) zinc chloride-treated corn stover after steam-exploded)

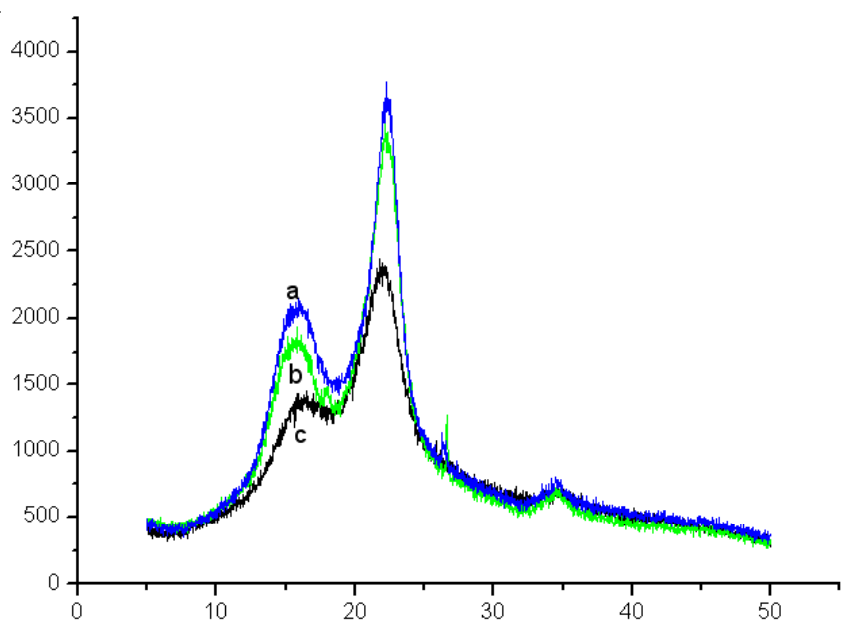

Fig. 4. X-Ray diffraction intensity curves of the samples (a: untreated, b: steam explosion treated, c: Zinc chloride-treated corn stover after steam-exploded)

\section{Conclusion}

The response surface methodology based on a threevariable central composite design was used to optimal the effect of zinc chloride concentration, reaction time and reaction temperature. Second-order regression models were developed using Mintab 15 software for predicting the responses in all experimental regions. For each response the coefficients of the postulated model calculated and the high adequacy of the model was proven by presenting the statistical specifications of them. Statistical analysis showed that the highest solution of cellulose $0.762 \mathrm{~g}$, was obtained when zinc chloride concentration was $87 \%$, reaction temperature, $139{ }^{\circ} \mathrm{C}$ and reaction time, 49 min. Fig. 5 showed the scales on the fiber surface were damaged and small grooves were produced after the zinc chloride pretreatment. FTIR spectra revealed an increase in the absorbency intensity around $1250 \mathrm{~cm}^{-1}$, suggesting some changes in the sulfur-containing chemical groups in the treated sample. X-ray diffraction (Fig. 4) results showed that the intensity of major peak decreased as the pressure increased. These changes may be attributed to the breakage of disulfide bridges and the destruction of the crystals and the removal of some loose substances in the fiber surface.

\section{ACKNOWLEDGEMENTS}

This work was supported by grant from the National Natural Science Foundation of China (11032012, 30870609), Natural Science Foundation of CQ CSTC (2009BB4382, 2010BB5225), Science and Technology Program of CQ CSTC (2009AB5174) and Foundation of Chongqing Municipal Education Commission (KJ091415).

\section{REFERENCES}

1. B. Hahn-Hägerdal, M. Galbe, M.F. Gorwa-Grauslund, G. Lidén and G. Zacchi, Trend Biotechnol., 24, 549 (2006).

2. A.E. Farrell, R.J. Plevin, B.T. Turner, A.D. Jones, M. O'Hare and D.M Kammen, Science, 311, 506 (2006).

3. M. Chen, J. Zhao and L.M. Xia, Carbohyd. Polym., 71, 411 (2008).

4. K.A. Gray, L.S. Zhao and M. Emptage, Curr. Opin. Chem. Biol., 10, 141 (2006).

5. M.E. Himmel, S.Y. Ding, D.K. Johnson, W.S. Adney, M.R. Nimlos, J.W. Brady and T.D. Foust, Science, 315, 804 (2007).

6. B. Yang and C.E. Wyman, Bioresour. Technol., 99, 5756 (2008).

7. J. Börjesson, M. Engqvist, B. Sipos and F. Tjerneld, Enzyme Microb. Technol., 41, 186 (2007).

8. B. Philipp, Polym. News, 15, 170 (1990).

9. G. Kettenbach, P. KluÈfers and P. Mayer, Macromol. Symp, 120, 291 (1997).

10. K. Letters, Kolloidzeitschrift, LVIII, 229 (1932).

11. J.O. Warwicker, R. Jeffries, R.L. Colbran and R.N. Robinson, Shirley Institute Pamphlet, 93, 164 (1966).

12. S. Kuga, J. Colloid Interf. Sci., 77, 413 (1980).

13. B. Lukanoff, H. Schleicher and B. Philipp, Cellulose Chem. Technol., 17, 593 (1977).

14. S. Ferreira, A.P. Duarte, M.H.L. Ribeiro, J.A. Queiroz and F.C. Domingues, Biochem. Eng. J., 45, 192 (2009).

15. G.E.P. Box and D.W. Behnken, Technometrics, 2, 455 (1960).

16. S. Kim and M.T. Holtzapple, Bioresour. Technology, 96, 1994 (2005).

17. C.I. Ishizawa, M.F. Davis, D.F. Schell and D.K. Johnson, J. Agric. Food Chem., 55, 2575 (2007).

18. X.F. Sun, R.C. Sun, Y.Q. Su and J.X. Sun, J. Agric. Food Chem., 52, 839 (2004).

19. C. Liu, R. Sun, A. Zhang and J. Ren, Carbohyd. Polym., 68, 17 (2007).

20. F.B. Sun and H.Z. Chen, J. Chem. Technol. Biotechnol., 83, 707 (2008).

21. B.S. Donohoe, M.P. Tucker, M. Davis, S.R. Decker, M.E. Himmel and T.B. Vinzant, Tracking Lignin Coalescence and Migration Through Plant Cell Walls During Pretreatment, In: 29th Symposium on Biotechnology for Fuels and Chemicals, Denver, CO; 5B-01, p. 67 (2007). 